Vol 12, Issue 6, 2019

\title{
ALTERING THE EXPRESSION OF P-GLYCOPROTEIN RESPONSIBLE FOR CHEMOTHERAPEUTIC DRUG RESISTANCE IN HEPG2 CELL LINE POST-TREATMENT WITH UREA AND $\beta$-MERCAPTOETHANOL
}

\author{
PROMA CHAKRABORTY ${ }^{1}$, MANI RAMAKRISHNAN ${ }^{2 *}$, KUMAR KM ${ }^{1,3}$ \\ ${ }^{1}$ Department of Biotechnology, Reva University, Bengaluru, Karnataka, India, ${ }^{2}$ Department of Environmental Sciences, School of \\ Engineering, Presidency University, Bengaluru, Karnataka, India, ${ }^{3}$ Department of Biotechnology, Dayananda Sagar College of Engineering, \\ Bengaluru, Karnataka, India. Email: maniramiyer@yahoo.com \\ Received: 27 February 2019, Revised and Accepted: 07 May 2019
}

\section{ABSTRACT}

Objective: The objective of this study is to alter the expression of p-glycoprotein (p-gp) pump proteins in HepG2 cells after treating with urea and $\beta$-mercaptoethanol (BME) (lead compounds). The most common cause for resistance to a broad range of anticancer drugs is influenced by overexpression of p-gp pumps that detect and eject anticancer drugs from the cancer cell. Altering the expression of these proteins will reduce the efflux action and enhance the drug retention eventually killing the cancer cell.

Materials and Methods: 3-(4, 5-dimethylthiazolyl-2)-2, 5-diphenyl tetrazolium bromide (MTT) assay was carried out to measure the cell viability (HepG2 cells) post-treatment with the lead compounds followed by flow cytometric analysis for protein expression studies.

Results: MTT assay confirms that the viability of HepG2 cells reduces as the concentrations of the lead compounds are increased. Flow cytometric analysis confirms reduced p-gp expression in HepG2 cells post-treatment with urea and BME. Compare to BME, urea turns out to be a potential compound in altering the expression of p-gp.

Conclusion: The present cell line study confirms that urea and BME are potential compounds which are able to reduce the p-gp expression in HepG2 cells.

Keywords: HepG2 cells, P-glycoprotein pumps, Protein expression, Urea, $\beta$-mercaptoethanol.

(c) 2019 The Authors. Published by Innovare Academic Sciences Pvt Ltd. This is an open access article under the CC BY license (http://creativecommons. org/licenses/by/4. 0/) DOI: http://dx.doi.org/10.22159/ajpcr.2019.v12i6.32834

\section{INTRODUCTION}

The most common cause of resistance to a broad range of anticancer drugs is influenced by the expression of energy-dependent transporters that detect and eject anticancer drugs from cells. The members of the ATP-binding cassette transporters are highly involved in this process. Till date, 49 such members have been identified in humans. There are two functional domains present for these transporters. These domains include a highly conserved nucleotide binding domain and a variable transmembrane domain [1]. These pumps also have a substrate binding site which is facing toward the cytosolic face. On binding, the substrate hydrolysis of ATP at the nucleotide-binding site induces a conformational change in these pumps which induces the efflux action, thus driving the substrate out from the cytoplasm to the surrounding matrix. Under normal condition, these pumps are highly essential as they drive out toxins from the cell which may otherwise cause detrimental effects [2]. These pumps are predominant in our liver epithelium and intestinal epithelium where they are meant for pumping out the drugs and harmful molecules into the bile duct and intestinal lumen, thus protecting our body from adverse effects. Maintenance of blood-brain barrier also comes under the influence of these pumps $[3,4]$.

As a part of the normal physiological function, these pumps are meant for efflux action. Expression of these p-gp pumps increases when the tissues turn neoplastic. The overexpression is induced by intrinsic factors and acquired mechanism, i.e., on exposure to chemotherapeutic drugs [5]. Once these pumps are overexpressed, they are responsible for pumping the chemotherapeutic drugs outside the cell and thus inducing multidrug resistance (MDR). There are three types of transporters - MDR protein 1 (MDR1), MDR-associated protein 1 (MRP1), and breast cancer resistance protein (BCRP) - which are involved in drug resistance. All the three transporters are highly specific for their substrates which include a wide range of chemotherapeutic drugs such as vinca alkaloids, epipodophyllotoxins, anthracyclines, taxanes, and kinase inhibitors. MDR1 gene produces p-glycoprotein (p-gp) predominates in colon, liver, and kidney cells [6-8]. The tissues which do not express MDR1 (lung, breast, and prostate cells) become resistant to chemotherapeutic drugs due to overexpression of MRP1 and BCRP $[9,10]$.

Various techniques have been adopted to deactivate these pumps. In virtual screening, computational models are used to predict the biological activity of various compounds. In a study by Kumar et al., a series of pyrrolopyrimidines were considered for ligand-based pharmacophore modeling to inhibit p-gp function [11]. In another study by Laksmiani et al. (2017) demonstrated molecular docking of brazilein (induced growth inhibition in breast cancer cells) to p-gp in the ATP-binding site. The interaction happens through hydrogen bonding between $\mathrm{O}$ atom in the carbonyl group of $\mathrm{C}_{9}$ atom of brazilein with $\mathrm{H}$ atom in Ser 423, Leu 504, and Asp 505 amino acid residues of p-gp protein [12].

Most efforts to inhibit p-gp have focused on the identification of modulator compounds that inhibit $p$-gp activity during chemotherapy. A good number of chemicals inhibit or deactivate p-gp and thus reverse MDR. Most of them are effective in vitro but have an adverse effect on the hosts. Some of these inhibitors have been non-selective, less potent with a reduced half-life period. In this current study, instead of deactivating the pump with an inhibitor native form of p-gp has been targeted using denaturing agent urea and $\beta$-mercaptoethanol (BME). Altering the native form will hinder its biological function and thus 


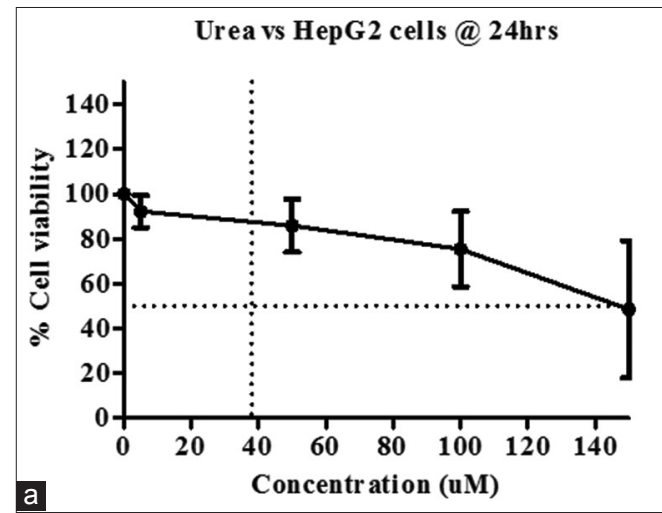

\section{乃 - mercaptoethanol vs HepG2 cells@24hrs}

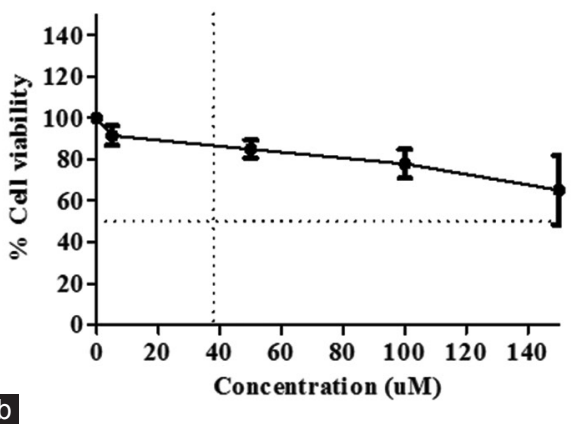

Fig. 1: Graph showing the effect of urea and $\beta$-mercaptoethanol (BME) on HepG2 cell viability $(n=3)(a)$ Cytotoxicity versus concentration of urea $(P=0.0048)$. (b) Cytotoxicity versus concentration of BME $(P=0.003)$

help in overcoming chemotherapeutic drug resistance. Urea is used to break non-covalent bonds, i.e., hydrogen bonds. BME, a disulfide reducing agent, can covalently interact with specific protein functional groups [13]. This chemical cocktail is ideally used for unfolding membrane proteins. Urea does not disrupt the membrane itself but helps to solubilize the hydrophobic membrane protein in water [14]. The misfolded protein does not reach the cell surface and is retained in the endoplasmic reticulum followed by rapid degradation. Unfolded pump proteins which cannot be expressed in the cell surface, will allow the chemotherapeutic drug retention in cancer cells which otherwise pump out the drugs from the cell into the matrix, thus gaining chemotherapeutic resistance.

In silico analysis by Kumar et al. proved that urea and BME can bind to p-gp with the best docking scores of -15.5995 and -10.0501 , respectively. Binding of BME caused a considerable perturbation in the backbone of the target with RMSD value eventually deviating to approximately 1.3 and urea further deviate the value to approximately 1.6. Furthermore, the decrease in the intramolecular hydrogen bonds over the simulation period confirms the secondary structural change [15].

\section{MATERIALS AND METHODS}

\section{Determination of cytotoxicity (MTT assay)}

The monolayer HepG2 cell culture in T25 flask was trypsinized and the cell count was adjusted, using DMEM (Dulbecco's Modified Eagle's Medium) containing fetal bovine serum such that $200 \mu \mathrm{l}$ of suspension contains approximately 20,000 cells. $200 \mu \mathrm{l}$ of cell suspension was seeded in a 96-well plate at required cell density $(20,000$ cells per well), without the test compounds (urea and BME). The cells were allowed to grow for about $24 \mathrm{~h}$. After $24 \mathrm{~h}$, when a partial monolayer was formed, the exhausted media was aspirated and $200 \mu \mathrm{l}$ of different concentrations ranging from $5 \mathrm{uM}$ to $200 \mathrm{uM}$ of test compounds were added. The controlled wells were treated only with the media without the test compounds. The plate was incubated for $24 \mathrm{~h}$ at $37^{\circ} \mathrm{C}$ in a $5 \%$ $\mathrm{CO}_{2}$ atmosphere. After the incubation period, the plates were taken out from incubator, and the spent media containing test compounds were removed and $100 \mu \mathrm{l}$ 3-(4, 5-dimethylthiazolyl-2)-2, 5-diphenyl tetrazolium bromide (MTT) reagent was added to a final concentration of $0.5 \mathrm{mg} / \mathrm{ml}$ of total volume. The plate was kept incubated for $2 \mathrm{~h}$ in a $\mathrm{CO}_{2}$ incubator. MTT reagent was removed and $100 \mu \mathrm{l}$ of dimethyl sulfoxide (DMSO) was added. Initially, the solution was yellow due to MTT as DSMO was added the purple crystals solubilized in it giving a purple color solution. The plate was incubated for $10 \mathrm{~min}$ before taking the OD readings. The absorbance reading was taken on an ELISA reader using $570 \mathrm{~nm}$ and $630 \mathrm{~nm}$ as reference wavelength followed by percentage calculation for cell viability [16-18]. \% of cell viability $=($ Absorbance of treated cells/absorbance of control cells $) \times 100$. GraphPad Prism software was used for plotting the MTT assay graph (concentration vs. cell viability) and $P$ value was calculated.
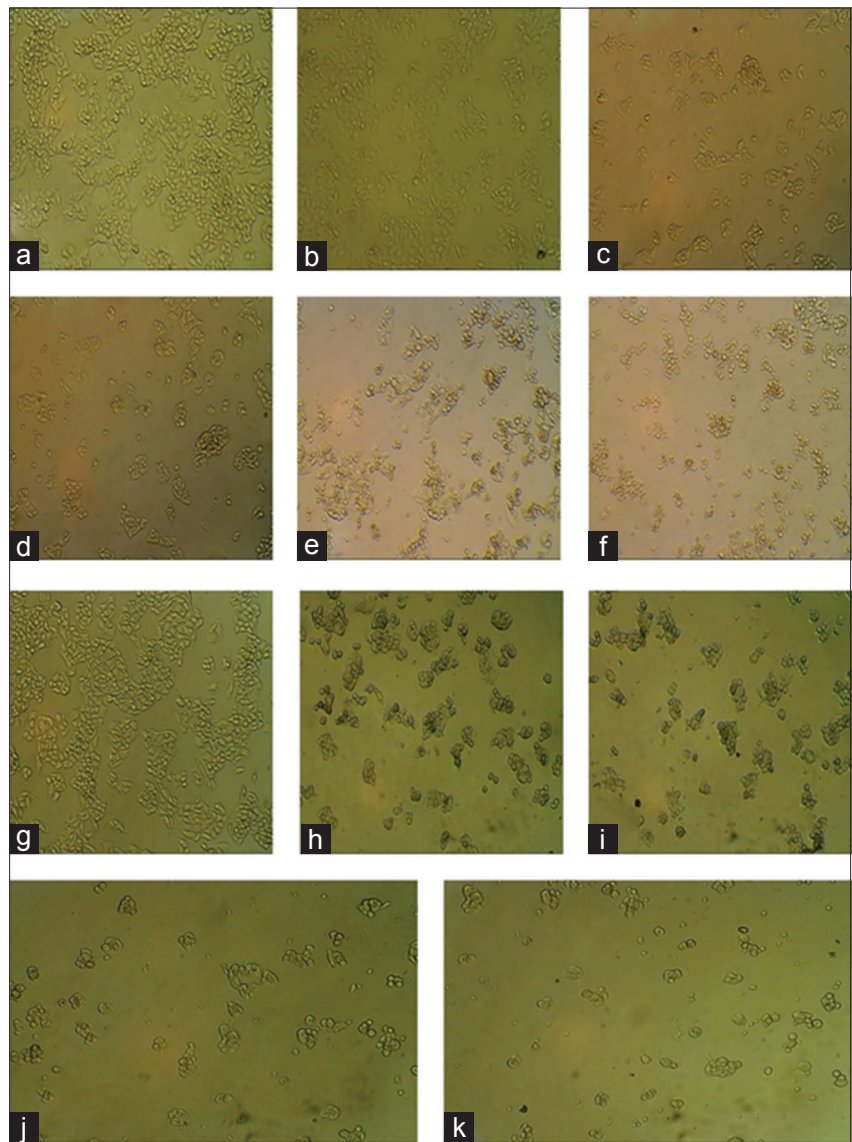

Fig. 2: 3-(4, 5-dimethylthiazolyl-2)-2, 5-diphenyl tetrazolium bromide assay - Cell viability by 3-(4, 5-dimethylthiazolyl-2)-2, 5-diphenyl tetrazolium bromide assay after $24 \mathrm{~h}$ treatment with urea and $\beta$-mercaptoethanol (BME). (a) Untreated HepG2 cells.

(b) HepG2 cells treated with 5 uM concentration of urea.

(c) HepG2 versus 50 uM urea. (d) HepG2 versus 100 uM urea.

(e) HepG2 versus 150 uM urea. (f) HepG2 versus 200 uM urea.

(g) HepG2 versus BME-5 uM. (h) HepG2 versus BME-50 uM.

(i) HepG2 versus BME-100 uM. (j) HepG2 versus BME-150 uM. (k) HepG2 versus BME-200 uM

\section{Protein expression study (flow cytometric analysis)}

Cells were cultured in a 6-well plate at a density of $3 \times 10^{5}$ cells $/ 2 \mathrm{ml}$ and incubated in a $\mathrm{CO}_{2}$ incubator overnight at $37^{\circ} \mathrm{C}$ for $24 \mathrm{~h}$. The spent medium was aspired out and the cells were treated with $50 \mathrm{uM}, 100 \mathrm{uM}$, and $150 \mathrm{uM}$ concentrations of experimental compounds (urea and $\mathrm{BME}$ ) and to the controlled well only $2 \mathrm{ml}$ media were added followed 


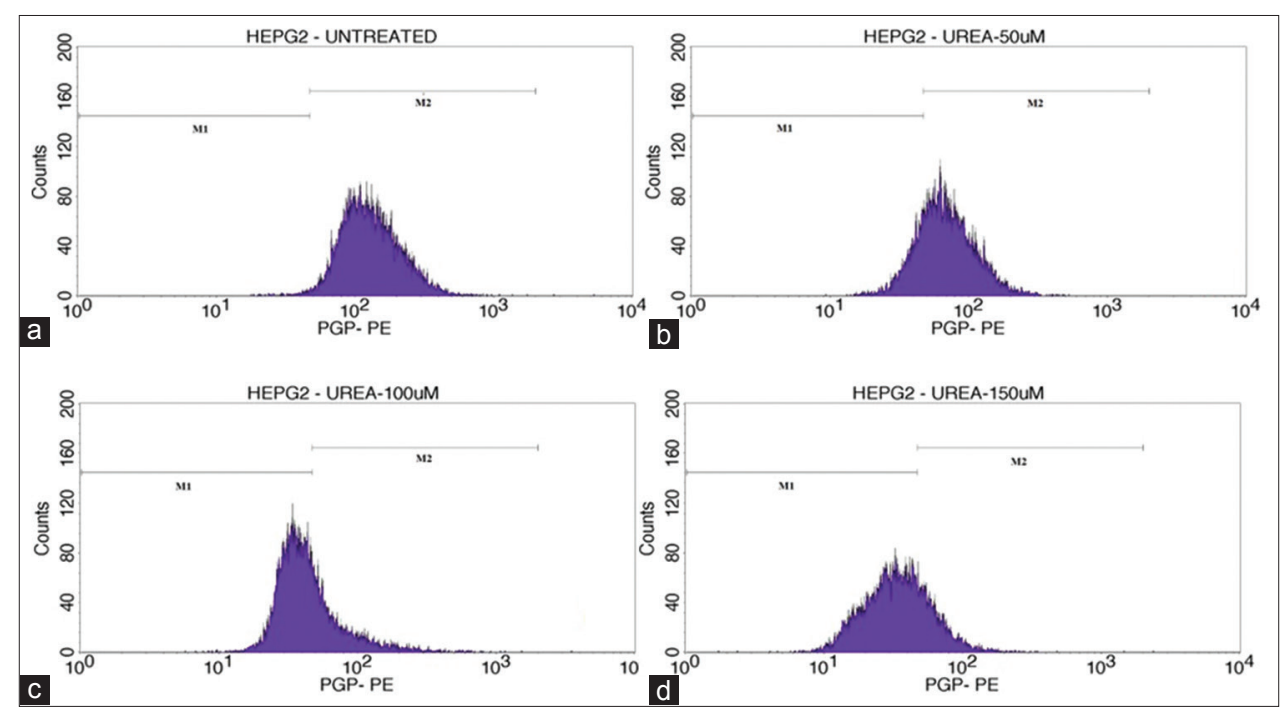

Fig. 3: PGP expression (PGP-PE) study on HepG2 cells after treating with test compound urea. PGP-PE histogram of the gated HepG2 singlets distinguishes cells at the M1 and M2 phases. Here, M2 refers to high expression/region and M1 refers to the low expression/region of p-glycoprotein. (a) Untreated cells. (b) Cells treated with $50 \mu \mathrm{M}$ concentration of urea. (c) Cells treated with $100 \mu \mathrm{M}$ concentration of urea. (d) Cells treated with $150 \mu \mathrm{M}$ concentration of urea

by incubation for $24 \mathrm{~h}$. The treated media were removed from the 6-well plate after $24 \mathrm{~h}$ and $1 \mathrm{ml}$ phosphate-buffered saline (PBS) was added to wash the cells followed by addition of $300 \mu$ trypsin for 3-5 min. After $5 \mathrm{~min}, 1 \mathrm{ml}$ low glucose media were added and the cell suspension was transferred into a centrifuge tube and centrifugation was done at $2000 \mathrm{rpm}$ for $5 \mathrm{~min}$. The supernatant was discarded and to the cell pellets, $5 \mu$ l of anti-p-gp was added and the tubes were incubated for $30 \mathrm{~min}$ in a dark environment. After the incubation period, $500 \mu \mathrm{l}$ of PBS was added in all the tubes, the content was mixed well and then transferred into fluorescence-activated cell sorting tubes for flow cytometric analysis [19-21].

\section{RESULTS}

\section{MTT assay}

The result of in vitro cytotoxicity study in HepG2 cell line reveals that both urea and BME is cytotoxic at higher concentration. The concentrations used for this study ranges from $5 \mathrm{uM}$ to $200 \mathrm{uM}$. In a comparatively lower dose, the cells were surviving but as we increased, the concentration cell death was visible. This indicates that the cytotoxic effect was dose dependent (Figs. 1 and 2).

\section{Flow cytometry}

Urea and BME-treated HepG2 cells were subjected to flow cytometric analysis for protein expression studies (p-gp). Three different concentrations were chosen for analysis $50 \mathrm{uM}, 100 \mathrm{uM}$, and $150 \mathrm{uM}$. As the concentration of the target compound - urea increases the native form of p-gp are altered and the surface isotopes are displaced. Anti-Pgp cannot bind to such displaced isotopes, thus p-gp mean fluorescence intensity decreases. Flow cytometric graph clearly indicates that untreated HepG2 cells are showing high p-gp expression with the histogram toward the M2 zone and as the concentration of urea increases the protein expression decreases as a result of which the histogram being gradually shifted toward the M1 zone (Figs. 3 and 4). However, in the case of BME-treated cells, $50 \mathrm{uM}$ concentration is showing a change in protein expression, but as the concentration increases, there is no such decrease in the expression levels of p-gp (Figs. 5 and 6).

\section{DISCUSSION}

An earlier study indicates that BME reduces oxidative stress and has a growth promoting action on mouse lymphoma L1210 cells in vitro [22]. Maintaining low levels of protein oxidation are, therefore, a key part of balanced protein expression in the cells [23]. Thus,

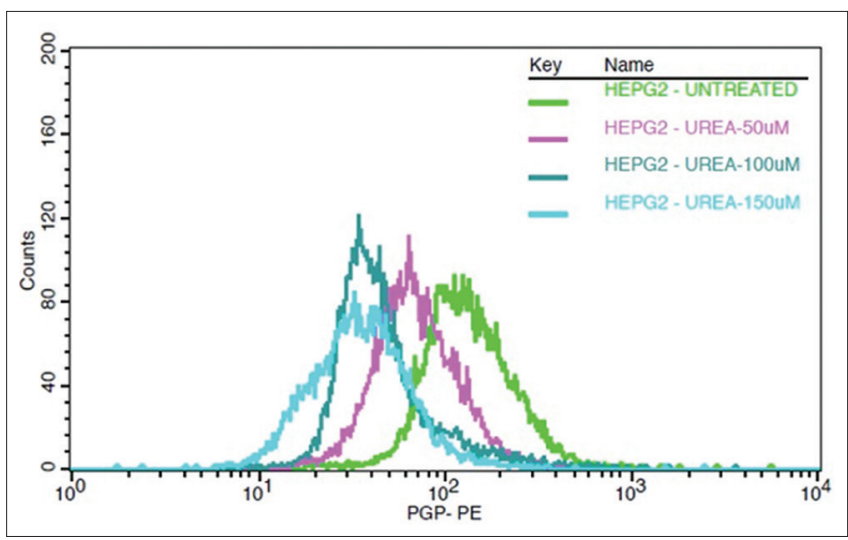

Fig. 4: Overlaid expression of PGP-PE in the untreated HepG2 Cells (green curve) and test compound urea-treated cells at different concentrations. The untreated cells are showing a higher expression of p-glycoprotein but as the concentration of urea is increased the expression level of p-glycoprotein gradually decreases

reduced oxidative stress may be one reason why BME is ineffective to p-gp expression at higher concentration. Chemotherapy would be much more effective if $\mathrm{p}$-gp pumps were shut down during the treatment. Most efforts to inhibit p-gp have focused on the identification of modulator compounds that inhibit p-gp activity during chemotherapy. In earlier studies, resistance modifying agent oxalyl bis (N-phenyl) hydroxamic acid (OPHA) has been used to inhibit p-gp. The high IC50 values of OPHA against different cell lines indicate the non-toxic nature of the compound. It has also been tested in mice model, but its exact effect on the human in vivo has not been confirmed [24]. There are some pharmacological agents who showed low protein affinities; others are nonselective and less potent. In this current study, urea and BME have been used to alter the native form of p-gp. Comparative analyses of the effect of urea and BME on p-gp expression have been depicted in Fig. 7. Urea is one of the endogenous compounds of the body with a normal range of 2.5-7.1 mmol/L. In one of the studies by Clark et al., oral dose of urea has been used in the treatment of secondary tumors in the liver. Urea was administered at a total dose of $8 \mathrm{gm}^{-2}$ in divided doses 4 times daily. Although the treatment was ineffective against metastatic liver, 


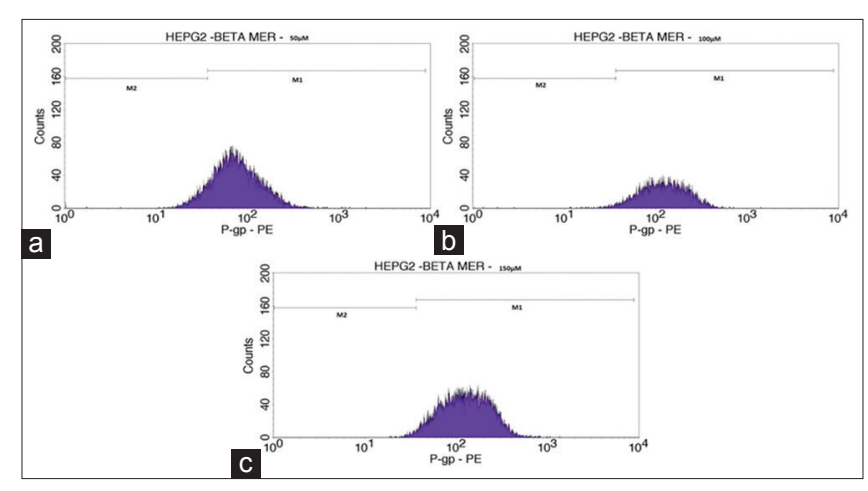

Figure 5: PGP expression study on HepG2 cells after treating with test compound $\beta$-mercaptoethanol (BME). PGP-PE histogram of the gated HepG2 singlets distinguishes cells at the M1 and M2 phases. Here, M2 refers to high expression/region and M1 refers to the low expression/region of p-glycoprotein. (a) Cells treated with $50 \mu \mathrm{M}$ concentration of BME. (b) Cells treated with $100 \mu \mathrm{M}$ concentration of BME. (c) Cells treated with $150 \mu \mathrm{M}$ concentration of BME

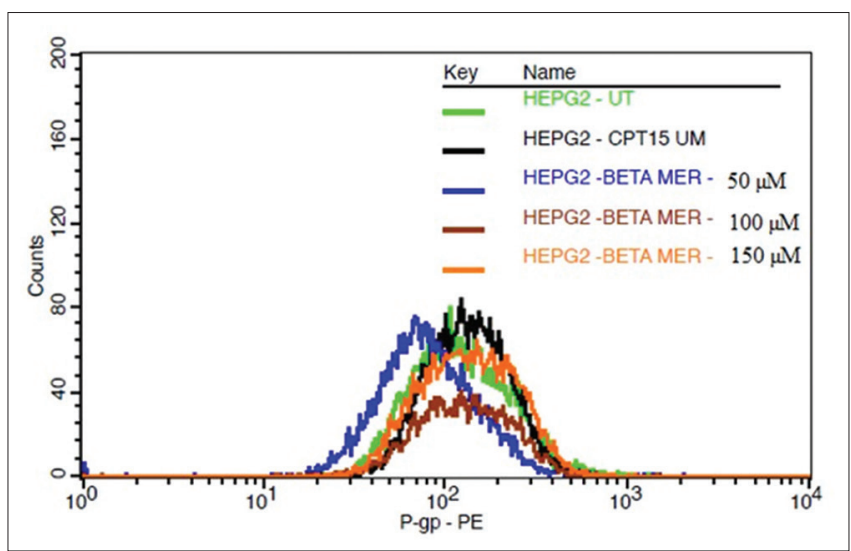

Fig. 6: Overlaid expression of PGP-PE in the untreated HepG2 cells (green curve) and test compound $\beta$-mercaptoethanol treated cells at different concentrations. $50 \mu \mathrm{M}$ concentration is only showing a change in the protein expression level; other concentrations are showing the expression similar to the untreated. $15 \mu \mathrm{M}$ of camptothecin has been used as a control

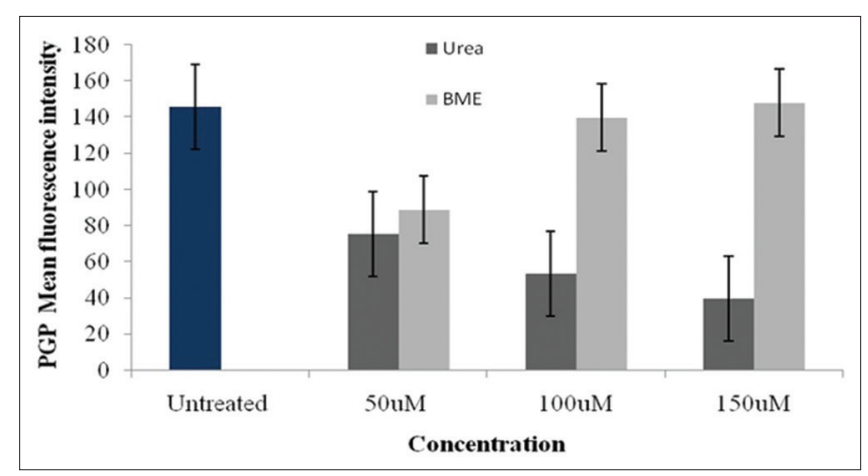

Fig. 7: Comparative analysis of the effect of urea and $\beta$-mercaptoethanol on p-glycoprotein expression

tumor plasma urea concentration was not affected. All the patients tolerated urea without any toxicity [25]. Anticancer property of BME has already been reported [26]. If urea and BME are specifically targeted against overexpressed p-gp in cancer cells, it may alter the native state, thus hindering its efflux action.

\section{CONCLUSION}

In this study, HepG2 cells are treated with urea and BME to alter the native form of p-gp. An altered form of p-gp would not be able to express itself on the cell surface. Without the active pump protein (p-gp), the cancer cell will retain the anticancer drugs which are otherwise being thrown out of the cell due to the efflux action. Conjugating urea and BME with a potential anticancer drug and its specific targeting to cancer cell can help in overcoming the property of multidrug resistance. Urea and BME can alter the p-gp expression and the anticancer drug can eventually kill the target cell without causing damage to the normal ones. Hence, the present study could be the basis for the development of novel methods for prevention of MDR in the cancer cell.

\section{AUTHORS' CONTRIBUTIONS}

Proma Chakraborty was involved in performing all the wet lab analysis, data compilation and statistical analysis included in this research work as well as writing the manuscript. Mani Ramakrishnan edited the manuscript. Mani Ramakrishnan and K. M. Kumar guided this research work.

\section{CONFLICTS OF INTERESTS}

The authors declare that there are no conflicts of interest.

\section{REFERENCES}

1. Chang G, Roth CB. Structure of MsbA from E. coli: A homolog of the multidrug resistance ATP binding cassette (ABC) transporters. Science 2001;293:1793-800.

2. Sauna ZE, Ambudkar SV. Characterization of the catalytic cycle of ATP hydrolysis by human P-glycoprotein. The two ATP hydrolysis events in a single catalytic cycle are kinetically similar but affect different functional outcomes. J Biol Chem 2001;276:11653-61.

3. Borst P, Elferink RO. Mammalian ABC transporters in health and disease. Annu Rev Biochem 2002;71:537-92.

4. Schinkel AH, Smit JJ, van Tellingen O, Beijnen JH, Wagenaar E, van Deemter L, et al. Disruption of the mouse mdr1a P-glycoprotein gene leads to a deficiency in the blood-brain barrier and to increased sensitivity to drugs. Cell 1994;77:491-502.

5. Abolhoda A, Wilson A, Ross H, Danenberg PV, Burt M, Scotto KW. Rapid activation of MDR1 gene expression in human metastatic sarcoma after in vivo exposure to doxorubicin. Clin Cancer Res 1999;5:3352-6.

6. Gottesman MM, Fojo T, Bates SE. Multidrug resistance in cancer: Role of ATP-dependent transporters. Nat Rev Cancer 2002;2:48-58.

7. Szakács G, Annereau JP, Lababidi S, Shankavaram U, Arciello A, Bussey KJ, et al. Predicting drug sensitivity and resistance: Profiling ABC transporter genes in cancer cells. Cancer Cell 2004;6:129-37.

8. Hilgendorf C, Ahlin G, Seithel A, Artursson P, Ungell AL, Karlsson J, et al. Expression of thirty-six drug transporter genes in human intestine, liver, kidney, and organotypic cell lines. Drug Metab Dispos 2007;35:1333-40.

9. Haber M, Smith J, Bordow SB, Flemming C, Cohn SL, London WB, et al. Association of high-level MRP1 expression with poor clinical outcome in a large prospective study of primary neuroblastoma. J Clin Oncol 2006;24:1546-53.

10. Housman G, Byler S, Heerboth S, Lapinska K, Longacre M, Snyder N, et al. Drug resistance in cancer: An overview. Cancers (Basel) 2014;6:1769-92.

11. Kumar V, Taya P, Neetu. 3D QSAR studies on pyrrolopyrimidines as selective p-glycoprotein antagonist. Int $\mathrm{J}$ Pharm Pharm Sci 2014;6:232-9.

12. Laksmiani NP, Meiyanto ED, Susidarti RA. Cytotoxic activity of Brazile in isolated from secang (Caesalpinia sappan) against MCF7/ DOX cells by inhibition of p-glycoprotein. Int J Pharm Pharm Sci 2017;9:124-30.

13. Szilagyi A, Kardos J, Osvath S, Barna L, Zavodszky P. Protein Folding: The Protein Folding Problem. Berlin Heidelberg: Springer-Verlag; 2007. p. 4-6.

14. Bowie JU. Membrane proteins: A new method enters the fold. PNAS 2004;101:3995-6.

15. Kumar KM, Ramakrishnan M, Chakraborty P, Chandramohan V. 
Docking and dynamic simulation analysis of p-glycoprotein pumpsresponsible for chemotherapeutic resistance post-treatment with urea and $\beta$-mercaptoethanol. J Appl Biol Sci 2018;12:26-35.

16. Alley MC, Scudiere DA, Monks A, Czerwinski M, Shoemaker R, Boyd MR. Validation of an automated microculture tetrazolium assay (MTA) to assess growth and drug sensitivity of human tumor cell lines. Proc Am Assoc Cancer Res 1986;27:389.

17. Scudiero DA, Shoemaker RH, Paull KD, Monks A, Tierney S, Nofziger TH, et al. Evaluation of a soluble tetrazolium/formazan assay for cell growth and drug sensitivity in culture using human and other tumor cell lines. Cancer Res 1988;48:4827-33.

18. Shah WA, Dar MD. Antiproliferative and antioxidant activities of Picea smithiana (Wall) Boiss oil. Int J Chem Pharm Sci 2014;2:541-6.

19. Filipits M, Suchomel RW, Dekan G, Haider K, Valdimarsson G, Depisch D, et al. MRP and MDR1 gene expression in primary breast carcinomas. Clin Cancer Res 1996;2:1231-7.

20. Beck WT, Grogan TM, Willman CL, Cordon-Cardo C, Parham DM, Kuttesch JF, et al. Methods to detect P-glycoprotein-associated multidrug resistance in patients' tumors: Consensus recommendations. Cancer Res 1996;56:3010-20.

21. Chan HS, Haddad G, Zheng L, Bradley G, Dalton WS, Ling V, et al. Sensitive immunofluorescence detection of the expression of P-glycoprotein in malignant cells. Cytometry 1997;29:65-75.

22. Ishii T, Bannaia S, Sugita Y. Mechanism of growth stimulation of L1210 cells by 2-mercaptoethanol in vitro. J Biol Chem 1981;256:12387-92.

23. Vogel C, Silva GM, Marcotte EM. Protein expression regulation under oxidative stress. Mol Cell Proteomics 2011;10:M111.009217.

24. Choudhuri SK. Deactivation of P-glycoprotein by a novel compound, oxalyl bis (N-phenyl) hydroxamic acid. Neoplasma 2002;49:272-7.

25. Clark PI, Slevin ML, Webb JA, Osborne RJ, Jones S, Wrigley PF, et al. Oral urea in the treatment of secondary tumours in the liver. Br J Cancer 1988;57:317-8.

26. Click RE. Dietary supplemented 2-mercaptoethanol prevents spontaneous and delays virally-induced murine mammary tumorigenesis. Cancer Biol Ther 2013;14:521-6. 